\title{
A Comparison Study of Impact Factor in Web of Science and Scopus Databases for Engineering Education and Educational Technology Journals
}

\author{
Pao-Nan Chou \\ National University of Tainan, Tainan, Taiwan (R.O.C.)
}

pnchou@mail.nutn.edu.tw

\begin{abstract}
The purpose of the current study is to explore the difference of the impact factor between Web of Science and Scopus databases for engineering education and educational technology journals. The study analyzes six engineering educational journals and seven educational technology journals which are indexed both in Web of Science and Scopus. For engineering education journals, analysis dates are limited to 2006 through 2008; as for educational technology journals, date is only limited to 2010. The research results indicate that the ranking of the impact factor for the selected journals indexed both in Web of Science and Scopus is extremely similar. A significant relationship exists between Web of Science and Scopus for selected journals' ranks in impact factor.
\end{abstract}

Keywords: Impact Factor, Engineering education, Educational Technology, Scopus, Web of Science

\section{Introduction}

Impact Factor (IF) developed by Eugene Garfield is a grading system whose original purpose is to evaluate scientific journals and identify important journal articles (Monastersky, 2005). After Thomson Reuters Corporation intensively employs the IF to promote its products, such as Science Citation Index (SCI) or Social Science Citation Index (SSCI), the IF effect dramatically influences the academic world. For example, two indicators for academic ranking of world universities conducted by Jiao Tong University are SCI and SSCI (ARWU, 2011). To make tenure decisions, some American universities even use the IF to evaluate faculty's publications (Gary \& Hodkinson, 2008).

However, due to the heavy use of the IF in research, several scholars proposed warnings on the value of the IF. Seglen (1997) summarized many problems associated with the IF and suggested that the IF should not be used to evaluate research. Coleman (1999) strongly criticized the IF for

Material published as part of this publication, either on-line or in print, is copyrighted by the Informing Science Institute. Permission to make digital or paper copy of part or all of these works for personal or classroom use is granted without fee provided that the copies are not made or distributed for profit or commercial advantage AND that copies 1) bear this notice in full and 2) give the full citation on the first page. It is permissible to abstract these works so long as credit is given. To copy in all other cases or to republish or to post on a server or to redistribute to lists requires specific permission and payment of a fee. Contact Publisher@InformingScience.org to request redistribution permission. its abuse in research and contented that using the IF to quantify journals' scientific impact was inappropriate. Therefore, whether or not the IF can be a reliable tool to judge researchers' works remains questionable.

Currently, researchers can obtain journals' IFs by using online tools in two databases. One database called Web of Science (WoS), Thomson Reuters's product, annually analyzes and pub- 
lishes indexed journals' IFs (Thomson Reuters, 2011a). Another database called Scopus, Elsevier publisher's product, records the information of journal citations, but does not report indexed journals' IFs, which can be obtained by manual calculation for journal citations or other websites' provided tools (SCImago, 2011).

Recently, since WoS's reported IFs is commercial-orientated (i.e. payment-based Journal Citation Report), several scholars began to question its objectivity by comparing other databases' reported IFs. Pislyakov (2009) reported that the IF ranking of those indexed journals between Scopus and WoS was partially different. Grady and Hodkinson's (2008) study revealed that no significant difference on journals' IF ranking between WoS and Scopus existed. However, abovementioned studies only focus on the field of business and science. Little was known about engineering and education.

In order to add knowledge base regarding the IF issue in the field of engineering and education, the current study aims to explore the difference of the IF between WoS and Scopus for engineering education and educational technology journals. The study analyzes six engineering educational journals and seven educational technology journals which are indexed both in WoS and Scopus. One research assumption is that journals' IF ranking in two databases is related since one previous study yielded a similar finding in other academic fields (Gary \& Hodkinson, 2008). The research hypothesis of the study is:

No significant difference exists for indexed journals’ IF ranking in WoS and Scopus.

\section{Literature Discussion}

\section{Concept of Impact Factor}

According to Thomson Reuters's official website (Thomson Reuters, 2011b), the definition of IF is "calculated by dividing the number of current year citations to the source items published in that journal during the previous two years". For example, if researchers attempt to obtain the IF of year 2011 for one specific journal, the calculation procedure is listed in Table 1.

Table 1 Example of IF Calculation for One Specific Journal

\begin{tabular}{|l|l|}
\hline Procedure & Calculation \\
\hline Step 1 (In Database) & $\begin{array}{l}\text { Citations in 2011 to journal articles published in 2010:56; in 2009:90 } \\
\text { Sum1 }=56+90=146\end{array}$ \\
\hline Step 2 (In the Journal) & $\begin{array}{l}\text { Number of citable journal articles published in 2010:35; in 2009:28 } \\
\text { Sum2=35+28=63 }\end{array}$ \\
\hline Step 3 & $\mathrm{IF}=$ Sum1/Sum2=146/63=2.32 \\
\hline
\end{tabular}

Currently, Thomson Reuters's WoS annually publishes one report called Journal Citation Report (JCR) in which indexed journals' IF (SSCI or SCI) is reported. In contrast with JCR, Elsevier's Scopus does not produce any IF data each year. However, Scimago Lab (2011) freely provides a web-based ranking tool which allows users to obtain IF information in Scopus database.

\section{Criticism of Impact Factor}

Opthof (1997) strongly criticized the use of IF in evaluating researchers' academic works. He further contented that the IF is not a reliable tool for the assessment of the quality of individual 
paper and scientists. Seglen (1997) summarized many problems associated with the IF. Some of the problems are (p. 499):

1. Review articles are heavily cited and inflate the impact factor of journals.

2. Long articles collect many citations and give high journal impact factors.

3. Short publication lag allows many short term journal self citations and gives a high journal impact factor.

Coleman (1999) argued that IF is a tool to identify important issues in research fields and however its heavy abuse in evaluate scholars' academic performances damages Eugene Garfield' s original purpose. Monastersky (2005) interviewed several scholars and journal editors regarding the IF issue. Many interviewees responded that IF often influenced research directions and stymie creative manuscripts. A recent study conducted by Meho and Yang (2007) showed that the use of Scopus and Google Scholar can yield a more accurate of the article impact rather than the use of WoS.

\section{Related Studies}

In the existing literature, two previous studies explored the related issue in other academic fields. Pislyakov (2009) compared the IF of 20 economic journals indexed both in Scopus and WoS. The findings showed that the IF ranking of those indexed journals between Scopus and WoS was partially different. Grady and Hodkinson (2008) analyzed the IF of ecology and environmental sciences journals indexed both in Scopus and WoS, and reported that even though several indexed journals varied in IF ranking, there was no significant difference on journals' IF ranking between WoS and Scopus.

\section{Research Method}

\section{Journal Analysis Principle}

In the present study, six engineering education journals and eight educational technology journals indexed both in Scopus and WoS are selected for further analysis. All selected journals' IF numerical values are obtained from JCR and Scimago Lab. For engineering education journals, analysis dates are limited to 2006 through 2008 since JCR lacks the IF report for International Journal of Engineering Education from 2009 to 2010; as for educational technology journals, date is only limited to 2010 mainly because some journals (e.g. Journal of Educational Computing Research and Turkish Online Journal of Educational Technology) begin to be indexed in both WoS and Scopus in 2010.

\section{Journal Selection: Engineering Education Journals}

In the field of engineering education, the number of journals indexed in WoS or Scopus database is different. Six engineering education journals are indexed in WoS; eleven in Scopus. A list of these indexed journals is organized into Table 2. This study only analyzes the journals indexed both in WoS and Scopus. Figure 1 shows the number of overlap for the journals indexed both in WoS and Scopus. 
Impact Factor in Web of Science and Scopus Databases

Table 2 List of Engineering Education Journals Indexed in Scopus or WoS

\begin{tabular}{|l|l|}
\hline Journals indexed in Scopus & Journals indexed in WoS \\
\hline 1. Journal of Engineering Education (JEE) & 1. Journal of Engineering Education \\
$\begin{array}{l}\text { 2. International Journal of Engineering Edu- } \\
\text { cation (IJEE) }\end{array}$ & $\begin{array}{l}\text { 2. International Journal of Engineering Edu- } \\
\text { cation }\end{array}$ \\
3. Chemical Engineering Education & $\begin{array}{l}\text { 3. Journal of Professional Issues in Engineer- } \\
\text { ing Education and Practice }\end{array}$ \\
$\begin{array}{l}\text { 4. Journal of Professional Issues in Engineer- } \\
\text { ing Education and Practice (JPIEEP) }\end{array}$ & $\begin{array}{l}\text { 4. Computer Applications in Engineering } \\
\text { 5ducation }\end{array}$ \\
$\begin{array}{l}\text { 5ducation (CAEE) } \\
\text { 6. International Journal of Electrical Engi- } \\
\text { neering Education (IJEEE) }\end{array}$ & 5. International Journal of Electrical Engi- \\
7. European Journal of Engineering Education. & 6. IEEE Transactions on Education \\
8. International Journal of Continuing Engineer- \\
ing Education and Life-Long Learning
\end{tabular}

Note: Journal title in bold is the overlap between Scopus and WoS

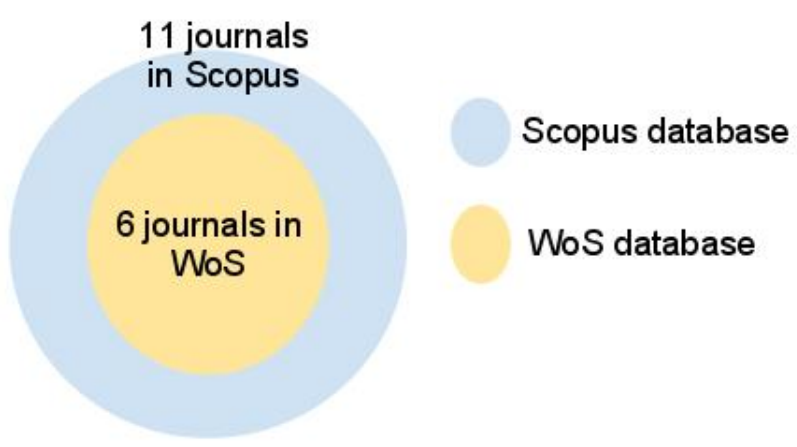

Figure 1 Number of overlap for journals both indexed in WoS and Scopus

\section{Journal Selection: Educational Technology Journals}

Compared to engineering education journals, in the field of educational technology, the number of journals indexed in WoS or Scopus is the same. Seven educational technology journals are indexed both in WoS and Scopus. A list of these indexed journals appears in Table 3. 
Table 3 List of Educational Technology Journals Indexed both in Scopus and WoS

\begin{tabular}{|l|}
\hline Journals indexed both in Scopus and WoS \\
\hline 1. Educational Technology Research and Development (ETRD) \\
2. British Journal of Educational Technology (BJET) \\
3. Educational Technology and Society (ETS) \\
4. Australasian Journal of Educational Technology (AJET) \\
5. Turkish Online Journal of Educational Technology (TOJET) \\
6. Journal of Educational Computing Research (JECR) \\
7. Computers \& Education (CE) \\
\hline
\end{tabular}

\section{Data Analysis Procedure}

Once the IF numerical values for selected journals indexed in both WoS and Scopus are obtained, three follow-up analysis procedures are conducted. First, each selected journal is ranked by the IF numerical values in Scopus and WoS. Second, a change in IF ranking between Scopus and WoS for each journal is examined. Finally, the Spearman rank-order correlation technique, whose purpose is to compare two rank-order variables, is performed to test the research hypothesis.

\section{Results \& Discussion}

\section{Findings in Engineering Education Journals}

Table 4 to Table 6 report the information regarding the IF comparison between WoS and Scopus for engineering education journals from 2006 to 2009. The information in three tables shows that Scopus IF is higher than WoS IF for six engineering education journals. Regardless of the type of database, JEE articles receive most attention from 2006 to 2007. In 2006, the ranking comparison between WoS and Scopus is the same, which in turn yields the highest correlation coefficient (coefficient $=1, \mathrm{p}<0.01$ ). In 2007 and 2008, the ranking comparison between WoS and Scopus is partially varied. In 2007, a change in rank is found for JPIEEP and CAEE; in 2008, there is a ranking change for JEE and ITE. However, despite a partial difference on IF rank in 2007 and 2008, Spearman correlation coefficient between WoS rank and Scopus rank is still high (coefficient $=0.94, \mathrm{p}<0.01)$.

Table 4 IF Comparison between WoS and Scopus in 2006

\begin{tabular}{|l|l|l|l|l|l|}
\hline Journal Title & WoS IF & Scopus IF & $\begin{array}{l}\text { WoS } \\
\text { Rank }\end{array}$ & Scopus Rank & $\begin{array}{l}\text { Change in } \\
\text { Rank }\end{array}$ \\
\hline JEE & 1.52 & 5.28 & 1 & 1 & 0 \\
\hline IJEE & 0.36 & 0.62 & 3 & 3 & 0 \\
\hline JPIEEP & 0.09 & 0.39 & 5 & 5 & 0 \\
\hline CAEE & 0.22 & 0.40 & 4 & 4 & 0 \\
\hline IJEEE & 0.05 & 0.11 & 6 & 6 & 0 \\
\hline ITE & 0.36 & 0.96 & 2 & 2 & 0 \\
\hline Spearman rank-order correlation coefficient $=1, \mathrm{p}<0.01$ & \\
\hline
\end{tabular}


Impact Factor in Web of Science and Scopus Databases

Table 5 IF Comparison between WoS and Scopus in 2007

\begin{tabular}{|l|l|l|l|l|l|}
\hline Journal Title & WoS IF & Scopus IF & $\begin{array}{l}\text { WoS } \\
\text { Rank }\end{array}$ & Scopus Rank & $\begin{array}{l}\text { Change in } \\
\text { Rank }\end{array}$ \\
\hline JEE & 3.00 & 6.29 & 1 & 1 & 0 \\
\hline IJEE & 0.36 & 0.61 & 3 & 3 & 0 \\
\hline JPIEEP & 0.18 & 0.49 & 5 & 4 & 1 \\
\hline CAEE & 0.31 & 0.47 & 4 & 5 & -1 \\
\hline IJEEE & 0.13 & 0.19 & 6 & 6 & 0 \\
\hline ITE & 0.77 & 1.35 & 2 & 2 & 0 \\
\hline Spearman rank-order correlation coefficient $=0.94, \mathrm{p}<0.01$ & \\
\hline
\end{tabular}

Table 6 IF Comparison between WoS and Scopus in 2008

\begin{tabular}{|l|l|l|l|l|l|}
\hline Journal Title & WoS IF & Scopus IF & $\begin{array}{l}\text { WoS } \\
\text { Rank }\end{array}$ & Scopus Rank & $\begin{array}{l}\text { Change in } \\
\text { Rank }\end{array}$ \\
\hline JEE & 1.09 & 4.79 & 2 & 1 & 1 \\
\hline IJEE & 0.55 & 0.76 & 3 & 3 & 0 \\
\hline JPIEEP & 0.16 & 0.36 & 5 & 5 & 0 \\
\hline CAEE & 0.39 & 0.42 & 4 & 4 & 0 \\
\hline IJEEE & 0.12 & 0.13 & 6 & 6 & 0 \\
\hline ITE & 1.40 & 1.55 & 1 & 2 & -1 \\
\hline Spearman rank-order correlation coefficient $=0.94, \mathrm{p}<0.01$ & \\
\hline
\end{tabular}

\section{Findings in Educational Technology Journals}

A summary of IF comparison between WoS and Scopus for educational technology journals in 2010 appears in Table 7.

Table 7 IF Comparison between WoS and Scopus in 2010

\begin{tabular}{|l|l|l|l|l|l|}
\hline Journal Title & WoS IF & Scopus IF & $\begin{array}{l}\text { WoS } \\
\text { Rank }\end{array}$ & Scopus Rank & $\begin{array}{l}\text { Change in } \\
\text { Rank }\end{array}$ \\
\hline ETRD & 1.08 & 1.89 & 4 & 4 & 0 \\
\hline BJET & 2.14 & 1.95 & 2 & 3 & -1 \\
\hline ETS & 1.07 & 1.64 & 5 & 5 & 0 \\
\hline AJET & 1.66 & 2.08 & 3 & 2 & 1 \\
\hline TOJET & 1.02 & 1.07 & 6 & 6 & 0 \\
\hline JECR & 0.56 & 0.62 & 7 & 7 & 0 \\
\hline CE & 2.62 & 3.71 & 1 & 1 & 0 \\
\hline Spearman rank-order correlation coefficient=0.96, p<0.01 \\
\hline
\end{tabular}


As shown in Table 7, Scopus IF is higher than WoS IF for most of educational technology journals. Regardless of the type of database, CE is the most popular educational technology journal. Sorting journals by IF number identifies a change in rank for BJET and AJET. A significant relationship between WoS rank and Scopus rank for selected journals is found (coefficient $=0.96$, $\mathrm{p}<0.01)$.

\section{General Discussion}

The results discussed above indicate that the variation between WoS rank and Scopus rank for engineering education and educational technology journals is small. There is a strong positive relationship between WoS rank and Scopus rank. In other words, no significant difference between WoS rank and Scopus rank for selected journals is found. Therefore, the research hypothesis in this study is retained. This finding is consistent with Grady and Hodkinson's (2008) study in which no significant difference between WoS rank and Scopus rank for ecology and environmental sciences journals was found.

An additional finding is that Scopus IF is higher than WoS IF for almost of engineering education and educational technology journals. One possible reason can be attributed to the journal coverage. Generally, Scopus's journal coverage is more expansive than WoS' s. However, in two previous related studies, no similar result was found (Gary \& Hodkinson, 2008; Pislyakov, 2009).

\section{Conclusion}

The current study aims to compare the difference of the IF ranking for engineering education and educational technology journals indexed both in WoS and Scopus. The research results indicate that the IF ranking of the selected journals in WoS and Scopus is extremely similar. If one specific journal obtains a higher IF in WoS, its IF in Scopus is also higher. Although Wos and Scopus database vary in the journal coverage, the IF ranking of the selected journals is almost the same. In other words, the IF number of top journals does not fluctuate wildly in two databases.

Today, researchers, educators, and librarians all rely upon WoS's IF alone to evaluate journals' quality. However, this study confirms that Scopus's IF is also a valuable tool to judge the importance of one specific journal due to the similarity of the IF ranking between WoS and Scopus. Compared to WoS' JCR (commercial product), for those who are interested in the field of engineering education and educational technology, the Scopus's citation report (free) provided by Scimago Lab is an alternative option to obtain a journal's IF.

Three recommendations for follow-up studies are proposed. First, future studies may choose nursing or medical education as focus areas to explore the IF difference between WoS and Scopus. Whether or not different research fields yield different findings is worthy of further investigation. Second, the analysis date for the selected journals of educational technology and engineering education in this study is limited. Future studies may extend the scope of the analysis date. Last, due to the limited research resources, this study could not obtain journals' IF from other databases. Future studies may attempt to analyze the IF difference by comparing three databases (e.g. EBSCO, WoS, Scopus) 


\section{References}

Academic Ranking of World Universities (ARWU). (2011). 2011 ranking. Retrieved September 5, 2011, from www.arwu.org

Coleman, R. (1999). Impact factors: Use and abuse in biomedical research. The Anatomical Record, 257, 54-57.

Gary, E., \& Hodkinson, S. Z. (2008). Comparison of journal citation reports and Scopus impact factors for ecology and environmental sciences journals. Issues in Science and Technology Librarianship, 54. Online Version.

Meho, L. I., \& Yang, K. (2007). Impact of data sources on citation counts and rankings of LIS faculty: Web of Science versus Scopus and Google Scholar. Journal of The American Society for Information Science and Technology, 58(13), 2105-2125.

Monastersky, R. (2005). The number that's devouring science: The impact factor, once a simple way to rank scientific journals, has become an unyielding yardstick for hiring, tenure, and grants. The Chronicle of Higher Education, 52(8), A12 .

Opthof, T. (1997). Sense and nonsense about the impact factor. Cardiovascular Research, 33(1), 1-7.

Pislyakov, V. (2009). Comparing two thermometers: Impact factors of 20 leading economic journals according to Journal Citation Reports and Scopus. Scientometrics, 79(3), 541-550.

SCImago. (2011). Journal scientific ranking. Retrieved September 5, 2011, from http://www.scimagojr.com/index.php

Seglen, P. O. (1997). Why the impact factor should not be used for evaluating research. BMJ, 213, 498-502.

Thomson Reuters. (2011a). Web of Science (WoS). Retrieved September 5, 2011, from http://wokinfo.com/products_tools/multidisciplinary/webofscience

Thomson Reuters. (2011b). Impact Factor. Retrieved September 5, 2011, from http://thomsonreuters.com/products_services/science/free/essays/impact_factor

\section{Biography}

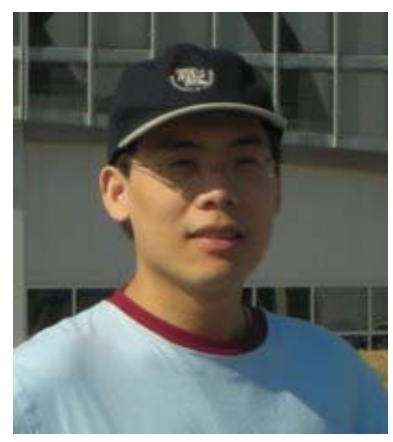

Pao-Nan Chou is an assistant professor at Department of Education at National University of Tainan, Taiwan. He received his B.S. in Electronic Engineering \& Computing Education and M.S. in Workforce Education \& Development from National Taipei University of Technology, Taiwan. He also received his M.Ed. and Ph.D. in Instructional Systems from The Pennsylvanian State University, USA. His research interests include e-learning and engineering education. 